\title{
Perceived health benefits of managed and unmanaged meadows in a mountain biosphere reserve - an experimental study in the Austrian Alps
}

\author{
Arne Arnberger, Renate Eder, Brigitte Allex, Hans-Peter Hutter, Peter Wallner, Nicole Baver, Johann G. Zaller \\ \& Thomas Frank
}

Keywords: biodiversity, naturalness, protected area, restorativeness, scenic beauty

\section{Abstract}

Many societies are faced with a growing prevalence of poor health because of stress and sedentary lifestyles. Natural and semi-natural landscapes are increasingly seen as restorative settings, compensating for negative psycho-physiological effects on humans. The extent of these positive effects, however, may depend on the landscape's degree of naturalness and perceptions of biodiversity, scenic beauty and restorativeness. We assessed the perceived health benefits for 22 participants (age $M=27$ years) who twice visited a managed and an abandoned meadow in the Austrian Großes Walsertal Biosphere Reserve. This study found that perceived health benefits did not differ between the managed and unmanaged meadows; participants reported a positive effect of their stays in both meadows on attention restoration, stress reduction and well-being. However, differences between the meadow types did emerge in terms of perceptions of their naturalness and biodiversity, and of perceptions of them as restorative places. Potentially, these restorative benefits can be used for new health-related offers for visitors to mountain biosphere reserves.

\section{Profile}

Protected area

Großes Walsertal

Biosphere Reserve

Mountain range

Alps

Country

Austria

\section{Introduction}

Industrialized countries are facing increasing prevalence of poor health due, inter alia, to mental stress, sedentary lifestyles and social inequalities (Imes \& Burke 2014; Velarde et al. 2007). Natural and seminatural landscapes are increasingly seen as restorative settings, potentially compensating for negative psycho-physiological effects on humans (Hartig \& Staats 2006; Van den Berg et al. 2010; Tyrväinen et al. 2014). The extent of these positive effects, however, may depend on the land-use intensity and degrees of naturalness and biodiversity.

Mountain meadows are an important agricultural land-use system in the Alps and can harbour high biodiversity (Boschi \& Baur 2008; Tocco et al. 2013). However, changes in agricultural practices and policies, and low farm income have resulted in the abandonment of traditionally managed mountain meadows globally and across the Alps (Bürgi et al. 2010; Hersperger \& Bürgi 2010; Arnberger \& Eder 2011; Rom et al. 2013). The question arises of whether mountain meadows can provide health benefits to humans, and whether there are differences in restorative effects between managed or unmanaged meadows. If specific types of meadows are effective in providing restorative effects, then these benefits can be used for the development of healthrelated commercial offers, thereby fostering the preservation of such landscape elements (Eder et al. 2015). Yet, the role of mountain landscapes for human health and the linkages between landscape beauty, actual and perceived naturalness and biodiversity, and self-reported health benefits have not so far been investigated.
Landscape-based human health effects

Two principal theories are used to explain landscape-based human health effects: the Attention Restoration Theory (Kaplan \& Kaplan 1989) and the Stress Reduction Theory (Ulrich et al. 1991). Restoring people's attentional capacity is one of the positive effects nature has on humans (Kaplan \& Kaplan 1989). Attention Restoration Theory asserts that people can concentrate better after a stay in nature compared to a stay in the built environment (Hartig et al. 1997; Kaplan \& Kaplan 1989). Settings that favour recovery from directed attention fatigue - restorative environments - feature four qualities: being away, extent / coherence, fascination and compatibility. Being away refers to one's ability to escape from everyday routines. Fascination indicates that people's attention is drawn to many interesting things and that they would like to get to know the landscape better. Extent refers to the extent to which environments are rich and coherent, such that they engage the mind and promote exploration. Extent / coherence describes the feeling of entering a new world, which is not chaotic and confusing. Environments that are compatible with visitors' needs and purposes support their intended activities (Hartig et al. 1997; Herzog et al. 2003; Kaplan \& Kaplan 1989).

The Stress Reduction Theory assumes that a visit to a natural environment can assist in recovering from stress (Ulrich et al. 1991). Even a green view from a window can contribute to recovering from surgery (Ulrich 1984). Research findings confirmed that exposure to natural urban settings, such as parks, can lead to positive changes in mood, stress reduction, lower heart rates, and increased attention, compared to built 


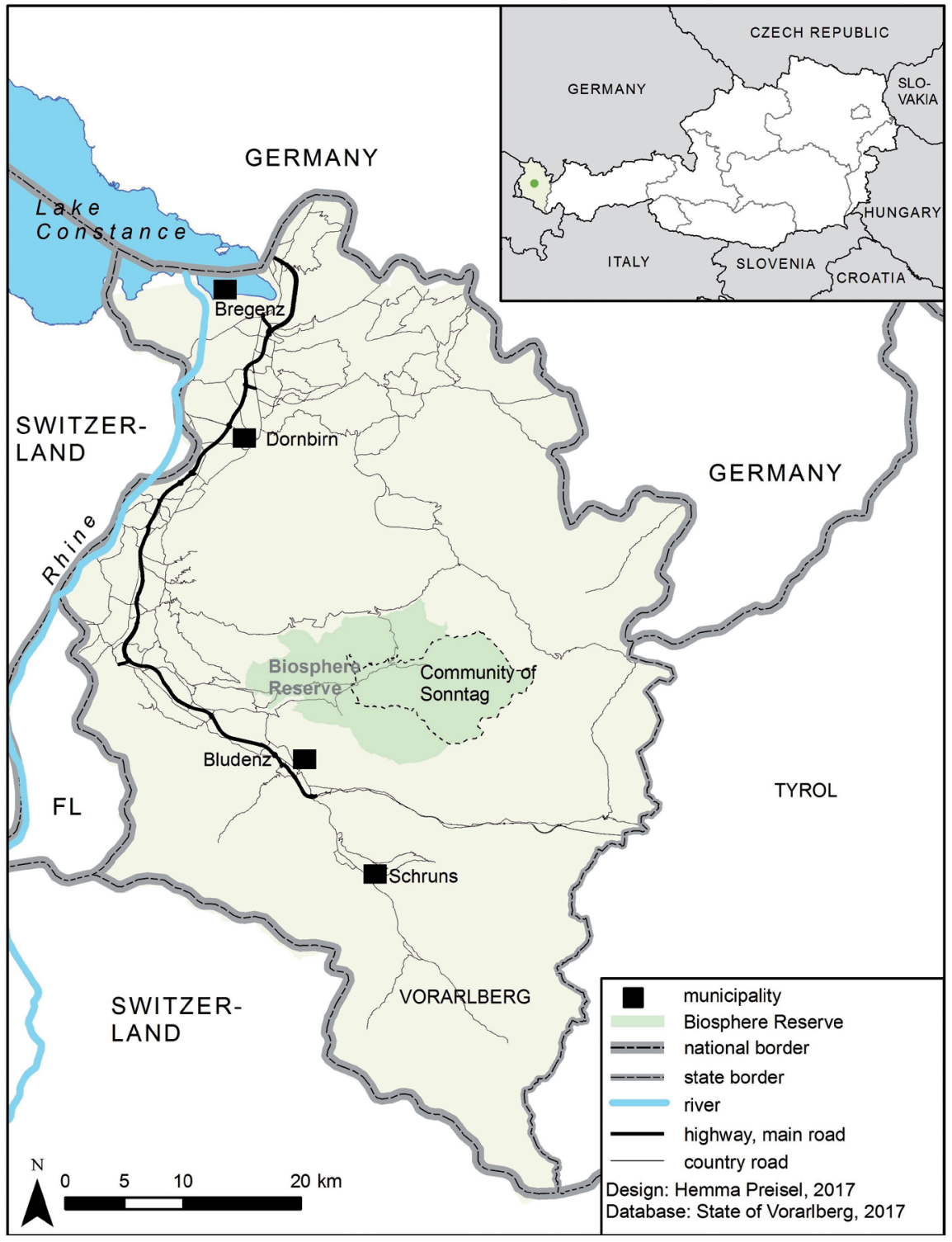

Figure 1 - Location of the Community of Sonntag within the Großes Walsertal UNESCO Biosphere Reserve, Austria. urban environments (Hartig et al. 2003; Ulrich et al. 1991; Van den Berg et al. 2003).

Linkages between human health and landscape quality indicators

Linkages between human health and (perceived) naturalness

Although there is a substantial amount of evidence for the restorative potential of natural areas in general, little is known about the effects of specific landscape types and of the degree of naturalness on human health and well-being (Marselle et al. 2015; Velarde et al. 2007). Martens et al. (2011) investigated the effect on self-rated well-being of a walk through managed and less-managed forest conditions in a Swiss urban forest. Results showed that well-being increased more in the managed forest stand than in the more natural forest. On the other hand, Carrus et al. (2013) found that the well-being of visitors to urban green spaces in Italy increased significantly as a function of the level of naturalness of the study sites. Hansmann et al. (2007) and Tyrväinen et al. (2014) found only limited evidence that forests have a more positive influence on human health compared to designed city parks. Marselle et al. (2015) even found no relationships between perceived naturalness and post-walk emotional well-being.

Linkages between human health and (perceived) biodiversity

Biodiversity is a key underlying condition for delivering ecosystem services (Millennium Ecosystem Assessment 2003), but little is known about the linkages between the actual or perceived biodiversity of a certain landscape and its effects on human health and well-being (Keniger et al. 2013; Lovell et al. 2014). The relationship between well-being and actual biodiversity (plant, butterfly and bird species richness) has been shown to be positive (Fuller et al. 2007) or inconsistent (Dallimer et al. 2012). In their study in Taiwan, Chang et al. (2016) did not observe any correlations between actual measures of biodiversity and meas- 


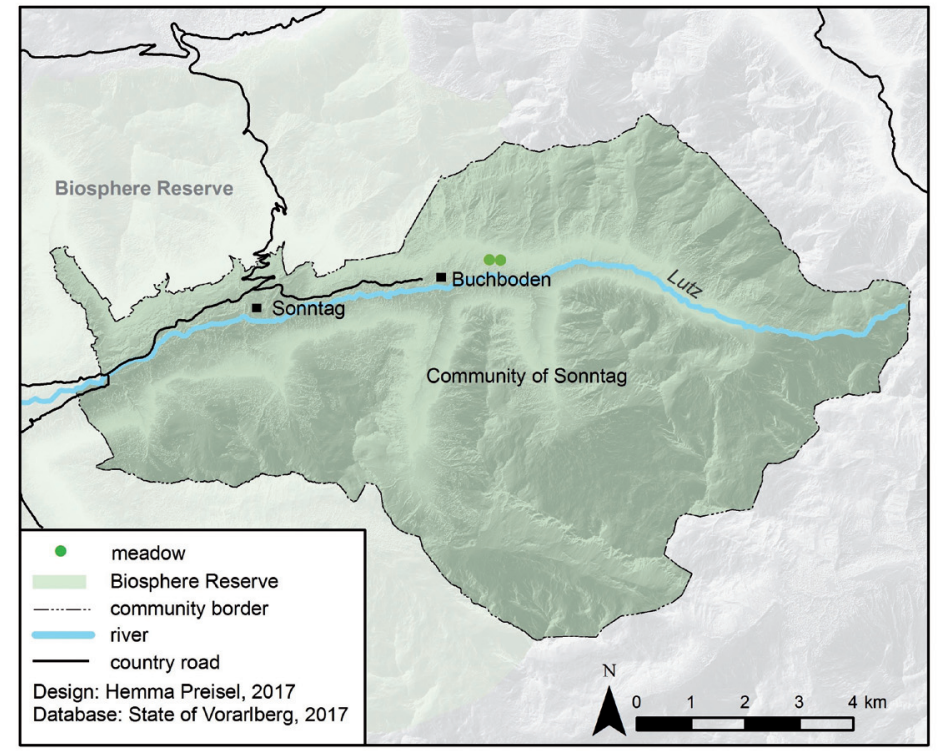

Figure 2 - Location of the two study sites within the Community of Sonntag in the Großes Walsertal Biosphere Reserve. ures of physiological health. In contrast, well-being was positively related to participants' perceived species richness (Carrus et al. 2015; Dallimer et al. 2012). However, Marselle et al. (2015) found that a perceived high level of bird biodiversity correlated to a postwalk negative affect. Johansson et al. (2014) presented images to analyse emotional and physiological responses to different states of biodiversity in temperate deciduous broad-leaf peri-urban forests in Sweden. Although participants had fairly accurate perceptions of biodiversity levels, they preferred an intermediate degree of biodiversity and showed higher brain activity in contexts of low biodiversity.

A more recent systematic review of the health and well-being benefits of biodiverse environments (Lovell et al. 2014) analysed 17 papers and found very limited evidence to suggest that biodiverse natural environments promote better health through exposure to pleasant environments or the encouragement of health-promoting behaviours. The authors also found evidence of inverse relationships and concluded that the evidence is inconclusive and fails to identify a specific role for biodiversity in the promotion of better health.

\section{Linkages between human health and landscape preferences/scenic beauty}

Several studies have investigated relationships between health benefits and preferences for a landscape type (Herzog et al. 2003; Van den Berg et al. 2003), and found that participants preferred natural environments to urban ones. Furthermore, few studies have correlated scenic beauty with health benefits. In his study among undergraduate students using landscape images as stimuli, Han (2010) found a strong, positive relationship between scenic beauty and restoration.

To summarize, these studies do not provide a clear pattern regarding the effects of different natural environments on human health and well-being. Specifical- ly, they could not detect any clear relationship between levels of naturalness, or perceived or measured biodiversity, and health benefits. In addition, these studies are difficult to compare due to their different methodological approaches, participant characteristics and study sites. Most of the few studies on relationships between biodiversity and human health and well-being were carried out in an urban context, often relying on independent samples of participants (Carrus et al. 2015; Dallimer et al. 2012; Fuller et al. 2007). Lovell et al. (2014) and Carrus et al. (2015) called for more research to produce a more robust evidence base for the relationship between biodiversity and human health.

\section{Research questions}

This experimental field study investigated shortterm psychological health effects of a stay by adult participants in a managed and an unmanaged mountain meadow in the Austrian Großes Walsertal UNESCO Biosphere Reserve (BR). The aim was to combine perceived health benefits with perceptions of naturalness, biodiversity, scenic beauty and restorativeness. The following research questions guided the study:

- Do participants' perceptions of landscape quality indicators (i.e., naturalness, biodiversity, scenic beauty and restorative quality) differ between a managed and an unmanaged meadow?

- Do participants assign the meadow types different effects on attention restoration, stress relief and well-being?

- Are there any linkages between self-reported health benefits and landscape quality indicators?

\section{Methodology}

\section{Study area}

The Großes Walsertal UNESCO BR in western Austria was chosen as a study site because its exten- 
single experiment (journey times to and from a site, plus observation time and completion of the survey) was about two hours.

Each survey day started at the same time in the morning. Participants arrived at the study site by bus, after a journey time of about 30 minutes. On arriving at the meadow, they then sat and observed the scenery on-site for 25 minutes, after which they filled in several survey forms, dealing with perceived restorativeness (PRS, Hartig et al. 1997), and perceptions of naturalness, biodiversity and aesthetics. Participants then went back to the bus, returning to their accommodation. In the afternoon, the same procedure was followed at the other site.

\section{Analyses}

We used ANOVAs with repeated measures to analyse differences in perceived naturalness, biodiversity, scenic beauty and restorativeness (PRS) between the four meadow visits. ANOVAs with repeated measures are susceptible to the violation of the assumption of sphericity. We therefore used Mauchly's tests of sphericity, testing whether the variances of the differences were equal. If violations of sphericity did occur, we used the Greenhouse-Geisser correction factor to produce a more valid F-value, as suggested by Rasch et al. (2010). Bonferroni post-hoc tests were used to identify differences between the visits; Cronbach's alpha assessed internal consistency of the four dimensions of the PRS for each separate meadow visit. All PRS dimensions had a high internal consistency statistic $(a>.70)$ across all meadow visits, except for one coherence dimension. Pearson correlations were used to analyse relationships between self-reported health
Table 1 - Perceived landscape quality indicators per meadow, day and day time $(N=22)$.

\begin{tabular}{|l|r|r|r|r|r|}
\cline { 2 - 5 } \multicolumn{1}{l|}{} & \multicolumn{2}{l|}{ Day 1 } & \multicolumn{2}{l|}{ Day 2 } & \multicolumn{1}{l|}{} \\
\hline Items (Mean) & $\begin{array}{l}\text { Abandoned, } \\
\text { morning }\end{array}$ & $\begin{array}{l}\text { Managed, } \\
\text { afternoon }\end{array}$ & $\begin{array}{l}\text { Managed, } \\
\text { morning }\end{array}$ & $\begin{array}{l}\text { Abandoned, } \\
\text { afternoon }\end{array}$ & $\begin{array}{l}\text { ANOVA } \\
\text { repeated } \\
\text { measures }\end{array}$ \\
\hline Naturalness & $1.23^{\circ}$ & $2.41^{\mathrm{b}}$ & $2.14^{\mathrm{b}}$ & $1.05^{\mathrm{a}}$ & $\begin{array}{r}\mathrm{F}=27.70, \\
\mathrm{p}<0.001\end{array}$ \\
\hline Biodiversity & $4.23^{\mathrm{a}, \mathrm{c}}$ & $3.23^{\mathrm{b}}$ & $3.77 \mathrm{~b}, \mathrm{c}$ & $4.59^{\mathrm{a}}$ & $\begin{array}{r}\mathrm{F}=12.63, \\
\mathrm{p}<0.001\end{array}$ \\
\hline $\begin{array}{l}\text { Landscape } \\
\text { beauty }\end{array}$ & $1.14^{\mathrm{a}}$ & $1.14^{\mathrm{a}}$ & $1.09^{\mathrm{a}}$ & $1.23^{\mathrm{a}}$ & $\begin{array}{r}\mathrm{F}=0.82, \\
\mathrm{p}=0.457\end{array}$ \\
\hline $\begin{array}{l}\text { Meadow } \\
\text { beauty }\end{array}$ & $2.27^{\mathrm{a}}$ & $1.95^{\mathrm{a}}$ & $2.00^{\mathrm{a}}$ & $2.14^{\mathrm{a}}$ & $\begin{array}{r}\mathrm{F}=0.58, \\
\mathrm{p}=0.532\end{array}$ \\
\hline
\end{tabular}

a, b.c Means with superscripts with the same letters do not differ at the $p<0.05$ level. Perceived naturalness: $1=$ very natural; $5=$ very unnatural

Perceived biodiversity: $1=$ very low; $5=$ very high

Perceived meadow / landscape beauty: $1=$ very high; $5=$ very low

benefits, PRS dimensions, and perceptions of naturalness, biodiversity and scenic beauty.

\section{Results}

Perceived landscape quality indicators

Participants perceived the meadows as natural, with high biodiversity, and as beautiful, in particular the scenery of the surrounding landscape (Table 1). While participants perceived the abandoned meadow as more natural and higher in biodiversity than the managed one, no differences were found for scenic beauty of the meadows and the surrounding landscape.

Participants perceived the meadows as restorative places and assigned both meadow types the four qualities of a restorative environment (Table 2). However,

Table 2 - Perceived restorativeness of the meadows indicated by the PRS per day and day time $(N=22)$.

\begin{tabular}{|c|c|c|c|c|c|}
\hline PRS items (Mean) & \begin{tabular}{|l|} 
Abandoned, \\
morning
\end{tabular} & \begin{tabular}{|l|}
$\begin{array}{l}\text { Managed, } \\
\text { afternoon }\end{array}$ \\
\end{tabular} & \begin{tabular}{|l|} 
Managed, \\
morning
\end{tabular} & \begin{tabular}{|l|} 
Abandoned, \\
afternoon
\end{tabular} & ANOVA \\
\hline \multicolumn{6}{|l|}{ Being Away (2 items) } \\
\hline A stay in this meadow is an escape from my everyday life. & 1.64 & 1.77 & 1.73 & 1.91 & $F=0.37, p=0.713$ \\
\hline Spending time here gives me a good break from my day-to-day routine. & 1.68 & 1.82 & 1.64 & 1.86 & $F=0.37, p=0.690$ \\
\hline \multicolumn{6}{|l|}{ Fascination (5 items) } \\
\hline The meadow fascinates me. & $2.36^{a}$ & $3.82^{\mathrm{b}}$ & $3.14^{b, c}$ & $2.32^{\mathrm{a}, \mathrm{c}}$ & $F=8.29, p=0.002$ \\
\hline My attention is drawn to many interesting things. & $2.36^{a}$ & $4.23^{b, c}$ & $3.27^{a, c}$ & $2.32^{a}$ & $F=10.52, p<0.001$ \\
\hline I would like to get to know this meadow better. & $2.64^{\mathrm{a}}$ & $4.18^{\mathrm{b}, \mathrm{c}}$ & $3.50^{\mathrm{a}, \mathrm{c}}$ & $2.91^{\mathrm{a}}$ & $F=6.11, p=0.006$ \\
\hline There is much to explore and discover. & $2.05^{a}$ & $4.23^{\mathrm{b}}$ & $3.59^{b}$ & $2.14^{\mathrm{a}}$ & $F=19.38, p<0.001$ \\
\hline I would like to spend more time looking at the surroundings. & 1.45 & 2.09 & 1.95 & 1.77 & $F=2.39, p=0.107$ \\
\hline \multicolumn{6}{|l|}{ Coherence (4 items) } \\
\hline There is too much going on. & 6.62 & 7.00 & 6.81 & 6.19 & $\mathrm{~F}=4.93, \mathrm{p}=0.024$ \\
\hline It is chaotic here. & $5.27^{a}$ & $7.00^{\mathrm{b}}$ & $6.86^{\mathrm{b}}$ & $5.05^{a}$ & $F=17.15, p<0.001$ \\
\hline There is a great deal of distraction. & $5.95^{\mathrm{a}, \mathrm{c}}$ & $6.91^{a, c}$ & $6.86^{\mathrm{b}, \mathrm{c}}$ & $5.95^{\mathrm{a}, \mathrm{c}}$ & $F=7.35, p=0.004$ \\
\hline It is a confusing place. & $5.45^{a}$ & $6.95^{\mathrm{b}}$ & $6.73^{b}$ & $5.14^{a}$ & $F=12.97, p<0.001$ \\
\hline \multicolumn{6}{|l|}{ Compatibility (5 items) } \\
\hline I have a sense that I belong here. & 4.05 & 3.95 & 3.91 & 4.36 & $F=0.62, p=0.503$ \\
\hline I have a sense of oneness with this setting. & 4.55 & 4.59 & 4.41 & 4.64 & $F=0.17, p=0.797$ \\
\hline Being here suits my personality. & 4.09 & 4.27 & 4.23 & 4.41 & $F=0.30, p=0.680$ \\
\hline I can do things I like here. & 3.59 & 3.14 & 3.18 & 3.73 & $F=2.12, p=0.132$ \\
\hline I could find ways to enjoy myself in a place like this. & 4.27 & 3.41 & 3.50 & 3.86 & $\mathrm{~F}=2.22, \mathrm{p}=0.120$ \\
\hline
\end{tabular}

Answer scale $1=$ totally agree; $7=$ totally disagree

a,b,c Means with superscripts with the same letters do not differ at the $p<0.05$ level. 
Table 3 - Perceived health effects per meadow, day and day time $(N=22)$.

\begin{tabular}{|l|r|r|r|r|r|}
\cline { 2 - 6 } \multicolumn{1}{l|}{} & \multicolumn{2}{l|}{ Day 1 } & \multicolumn{2}{l|}{ Day 2 } & \multicolumn{1}{l}{} \\
\hline $\begin{array}{l}\text { Health benefits } \\
\text { (Mean) }\end{array}$ & $\begin{array}{l}\text { Abandoned, } \\
\text { morning }\end{array}$ & $\begin{array}{l}\text { Managed, } \\
\text { afternoon }\end{array}$ & $\begin{array}{l}\text { Managed, } \\
\text { morning }\end{array}$ & $\begin{array}{l}\text { Abandoned, } \\
\text { afternoon }\end{array}$ & ANOVA \\
\hline $\begin{array}{l}\text { Attention } \\
\text { restoration }\end{array}$ & 1.50 & 1.73 & 1.91 & 1.91 & $\begin{array}{c}F=2.25, \\
p=0.113\end{array}$ \\
\hline Stress reduction & 1.50 & 1.59 & 1.55 & 1.82 & $\begin{array}{c}F=1.19, \\
p=0.319\end{array}$ \\
\hline Well-being & 1.45 & 1.36 & 1.55 & 1.73 & $\begin{array}{c}F=1.86, \\
p=0.164\end{array}$ \\
\hline
\end{tabular}

Answer scales: attention restoration: $1=$ very well, $5=$ not at all; stress reduction: $1=$ very well, $5=$ not at all; psychological well-being: $1=$ improved, $3=$ not changed, $5=$ declined.

Table 4 - Correlations between perceived health benefits, naturalness, scenic beauty and biodiversity $(\mathrm{N}=22)$.

\begin{tabular}{|l|r|r|r|r|}
\cline { 2 - 5 } \multicolumn{1}{l|}{} & \multicolumn{1}{|c|}{$\begin{array}{l}\text { Abandoned, } \\
\text { morning }\end{array}$} & $\begin{array}{r}\text { Managed, } \\
\text { afternoon }\end{array}$ & $\begin{array}{l}\text { Managed, } \\
\text { morning }\end{array}$ & $\begin{array}{l}\text { Abandoned, } \\
\text { afternoon }\end{array}$ \\
\hline Biodiversity $x$ naturalness & n.s. & n.s. & n.s. & n.s. \\
\hline Scenic beauty $x$ naturalness & n.s. & n.s. & $0.615^{* *}$ & $0.646^{* *}$ \\
\hline Scenic beauty $x$ biodiversity & n.s. & n.s. & n.s. & n.s. \\
\hline $\begin{array}{l}\text { Stress reduction } x \text { attention } \\
\text { restoration }\end{array}$ & $0.638^{* *}$ & $0.703^{*}$ & $0.743^{* *}$ & $0.800^{* *}$ \\
\hline Stress reduction $x$ well-being & $0.466^{*}$ & $0.620^{* *}$ & $0.683^{* *}$ & $0.603^{* *}$ \\
\hline $\begin{array}{l}\text { Attention restoration } x \text { well- } \\
\text { being }\end{array}$ & n.s. & $0.653^{* *}$ & $0.825^{* *}$ & $0.739^{* *}$ \\
\hline $\begin{array}{l}\text { Scenic beauty } x \text { stress } \\
\text { reduction }\end{array}$ & n.s. & $0.558^{* *}$ & n.s. & n.s. \\
\hline $\begin{array}{l}\text { Scenic beauty } x \text { attention } \\
\text { restoration }\end{array}$ & n.s. & $0.642^{* *}$ & $0.629^{* *}$ & $0.441^{*}$ \\
\hline Scenic beauty $x$ well-being & n.s. & $0.615^{* *}$ & $0.650^{* *}$ & $0.467^{*}$ \\
\hline $\begin{array}{l}\text { Naturalness } x \text { stress reduc- } \\
\text { tion }\end{array}$ & n.s. & n.s. & n.s. & $0.733^{* *}$ \\
\hline $\begin{array}{l}\text { Naturalness } x \text { attention } \\
\text { restoration }\end{array}$ & n.s. & n.s. & n.s. & $0.683^{* *}$ \\
\hline Naturalness $x$ well-being & n.s. & n.s. & n.s. & $0.723^{* *}$ \\
\hline $\begin{array}{l}\text { Biodiversity } x \text { stress reduc- } \\
\text { tion }\end{array}$ & n.s. & n.s. & n.s. & n.s. \\
\hline $\begin{array}{l}\text { Biodiversity } x \text { attention } \\
\text { restoration }\end{array}$ & n.s. & n.s. & n.s. & n.s. \\
\hline Biodiversity $x$ well-being & n.s. & n.s. \\
\hline
\end{tabular}

${ }^{*} p<0.05 ;{ }^{* *} p<0.01 ;$ n.s. $=$ not significant

different results were obtained regarding the four PRS qualities. No differences were observed for being away and compatibility items, while most items of fascination and coherence differed. Participants perceived the abandoned meadow as more fascinating. It offered them a lot more to explore and discover; they wanted to get to know the meadow better. But participants also perceived the abandoned meadow as more chaotic and confusing than the managed one, with a higher level of distraction. Differences between the morning and afternoon visits to the same meadow were marginal.

\section{Perceived health effects}

Participants reported a positive effect of their stays in the meadows on attention restoration, stress reduction and well-being. No differences between the meadows were found for perceived effects on attention restoration, stress relief and well-being (Table 3).
Relationships between perceived landscape quality indicators and health benefits

The number of significant correlations differed between the first and second visits to the abandoned site, while for the managed one the number of correlations was the same (Table 4). While for the first visit to the abandoned meadow only two significant correlations were found, nine rather strong correlations for the second visit were reported. Correlations between the items show that perceptions of biodiversity did not correlate with naturalness, scenic beauty or the perceived health effects, irrespective of the meadow type. Perceived scenic beauty and naturalness correlated positively only for the second day. At all sites, many positive and mainly strong correlations between the health items were found, except for the first visit to the abandoned meadow for attention restoration and well-being. Similarly, many positive correlations between scenic beauty and health items were found, except for the first site visit on day one. Correlations between naturalness and health benefits were only found for the second visit of the abandoned meadow.

In order to analyse the relationships between PRS dimensions, landscape quality indicators and health benefits, both visits per meadow type were aggregated. Few significant correlations emerged between the four PRS dimensions and self-reported health benefits and landscape quality indicators (Table 5). The more compatible participants perceived the abandoned meadow, the more they perceived the meadow as beautiful and natural. The more restorative the managed meadow was perceived (except for coherence), the more participants reported reductions in their stress level.

\section{Discussion}

This field experiment used a dependent sample of adult participants and compared their perceptions of health benefits and landscape quality indicators (naturalness, biodiversity, scenic beauty and restorativeness) in a managed and an unmanaged mountain meadow. Both meadows are in an area of remote alpine scenery, without traffic noise or tourism facilities, and with very low visitor levels. The study found differences between the meadow types but also commonalities in perceptions for health benefits and landscape quality indicators. Overall, respondents perceived both meadows as beautiful and as restorative, providing health benefits to them.

\section{Differences and commonalities between meadow types}

We found that perceived health benefits (i. e., attention restoration, stress reduction and well-being) were the same for the managed and the unmanaged meadows; the perceived benefits were fairly strong compared to an urban study among adolescents (Eder et al. 2016). So far, little research has analysed whether health benefits differ according to the type of natural 
Table 5 - Correlations between PRS dimensions and perceived biodiversity, naturalness, beauty of the meadow and self-reported bealth benefits; means of the PRS dimensions per meadow type $(N=22)$.

\begin{tabular}{|c|c|c|}
\hline Items & $\begin{array}{l}\text { Abandoned } \\
\text { meadow }\end{array}$ & $\begin{array}{l}\text { Managed } \\
\text { meadow }\end{array}$ \\
\hline Escape $x$ & $M=1.77$ & $M=1.74$ \\
\hline Biodiversity & n.s. & n.s. \\
\hline Naturalness & n.s. & n.s. \\
\hline Scenic beauty & n.s. & n.s. \\
\hline Attention restoration & n.s. & n.s. \\
\hline Stress reduction & n.s. & $0.464^{*}$ \\
\hline Well-being & n.s. & n.s. \\
\hline Fascination $\mathrm{x}$ & $M=2.23$ & $M=3.40$ \\
\hline Biodiversity & n.s. & n.s. \\
\hline Naturalness & n.s. & n.s. \\
\hline Scenic beauty & n.s. & n.s. \\
\hline Attention restoration & n.s. & n.s. \\
\hline Stress reduction & n.s. & $0.553^{* *}$ \\
\hline Well-being & n.s. & n.s. \\
\hline Coherence $\mathrm{x}$ & $M=5.70$ & $M=6.89$ \\
\hline Biodiversity & n.s. & n.s. \\
\hline Naturalness & n.s. & n.s. \\
\hline Scenic beauty & n.s. & n.s. \\
\hline Attention restoration & n.s. & n.s. \\
\hline Stress reduction & n.s. & n.s. \\
\hline Well-being & n.s. & n.s. \\
\hline Compatibility $\mathrm{x}$ & $M=4.15$ & $M=3.86$ \\
\hline Biodiversity & $0.491^{*}$ & n.s. \\
\hline Naturalness & $0.507^{*}$ & n.s. \\
\hline Scenic beauty & n.s. & n.s. \\
\hline Attention restoration & n.s. & n.s. \\
\hline Stress reduction & n.s. & $0.455^{*}$ \\
\hline Well-being & n.s. & n.s. \\
\hline
\end{tabular}

${ }^{*} p<0.05 ;{ }^{* *} p<0.01 ;$ n.s. $=$ not significant.

mountain environment; earlier on-site studies comparing natural and semi-natural sites did not provide a clear picture of perceived or observed health effects depending on the degree of naturalness (Carrus et al. 2013; Dallimer et al. 2012; Hansmann et al. 2007; Marselle et al. 2015; Martens et al. 2011; Tyrväinen et al. 2014; Velarde et al. 2007). Our results are in line with those studies which have not found empirical evidence of different health effects depending on the degree of naturalness. It seems that measuring differences in (perceived) health benefits of direct exposure to different natural and semi-natural places is difficult, which supports the need expressed by many authors for more comparative studies (Carrus et al. 2013; Hernandez \& Hidalgo 2005; Marselle et al. 2015; Verlarde et al. 2007).

Previous research found positive, negative or no relationships between actual or perceived biodiversity and psychological and physiological health measures (Carrus et al. 2015; Chang et al. 2016; Dallimer et al. 2012; Fuller et al. 2007; Johannsson et al. 2014; Lovell et al. 2014; Marselle et al. 2015). Although participants of this study reported differences in perceived biodiversity, they assigned both meadows the same health benefits. This study suggests that self-reported health benefits are independent of perceived naturalness and biodiversity. Participants perceived the abandoned meadow as having greater biodiversity than the managed one. Whether this is correct is difficult to confirm, but research on flora and fauna biodiversity in Alpine mountain meadows has often observed higher plant biodiversity in extensively managed meadows (Boschi \& Baur 2008; Tocco et al. 2013; Tasser \& Tappeiner 2002), even for that part of the BR (Walcher et al. 2017), while results for fauna biodiversity varied between meadow types (Ranta \& Vepsäläinen 1981). In addition, the managed meadow of this study had recently been cut and flowering plants were very rare, making it difficult for participants to recognize the plant biodiversity. Compared to studies assessing the restorative potential of urban or suburban sites (Eder et al. 2016; Hartig et al. 1997; Hernández \& Hidalgo 2005), we found higher positive evaluations for all four PRS dimensions. Compared to another Austrian project on mountain hikers (Wöran \& Arnberger 2012), participants of the Walsertal study rated the PRS dimensions higher, except for compatibility. Participants clearly perceived the two meadows as very restorative places which provide many health benefits. It can be assumed that the location, remote from any urban setting, and the high scenic quality of the surrounding landscape contributed to their positive evaluation. However, the meadows seemed to be less compatible with participants' goals compared to hikers' (Wöran \& Arnberger 2012). While hikers come to the mountains to pursue their preferred leisure activities, the participants in our study could not select the study sites or their activities, potentially resulting in lower scores for the compatibility dimension. Participants assigned the abandoned meadow the same health benefits, although they perceived it as more chaotic. At the same time, they also perceived it as more fascinating. One explanation might be that a fascinating landscape compensates for chaotic and unorganized conditions. However, we could not find a significant correlation between these two PRS dimensions.

\section{Relationships between landscape quality} indicators and health benefits

Participants' self-reported effects on attention restoration, stress reduction and well-being were highly correlated. The more participants were convinced that there was a positive health effect, the more additional health benefits were assumed. Thus, they perceived both meadows as multifunctional, affecting them positively on many health-related levels. Eder et al. (2016) observed similar correlations between these health benefits, but found that forests have a higher capacity for attention restoration than for stress reduction.

Perceived increased health benefits showed correlations with higher scenic quality, confirming the results of Han (2010). People perceive beautiful landscapes as being more beneficial for health. However, few significant correlations between health benefits and 
other landscape quality indicators were observed. Previous research has often demonstrated a relationship between restorativeness (PRS) and health outcomes (Berto 2005; Carrus et al. 2015), or between restorativeness and flow perceptions when hiking (Wöran \& Arnberger 2012). Observed relationships in this study, however, were scarce and differ between the meadow types. The more restorative the managed meadow was perceived as being, the more participants reported reductions in stress levels. While this relationship is in line with previous research, the question arises as to why there is no relationship between PRS and attention restoration and well-being, and why there is no association between PRS and self-reported health benefits for the abandoned site. One explanation might lie in the perceptions of the sites as very restorative and healthy, resulting in very few variations in participants' responses. The small sample size might be another explanation.

While several studies have found a positive relationship between duration and / or frequency of exposure and health benefits (Barton \& Pretty 2014), with exceptions (Marselle et al. 2015), this study did not find differences in health benefits between the first day and the second. One explanation might be that, because of the study design, our participants were not attentionally exhausted and stressed when they arrived at the BR. However, on the second day, an increase was observed in correlations between perceptions of naturalness and health benefits for the abandoned site. The repeat exposure might have led to more distinct perceptions of the abandoned site. Future studies could test whether there is a significant change or even decrease in perceptions of health effects of mountain meadows due to repeated exposure.

\section{Conclusions}

Although research has shown that natural environments achieve greater improvement of the psychological and physiological state of humans than built environments (e. g., Ulrich et al. 1991; Hartig \& Staats 2006; Van den Berg et al. 2003; 2010; Tyrväinen et al. 2014), little is known about the health benefits of natural and semi-natural mountain landscape types. In addition, few studies have tested the relationships between human health and well-being on the one hand and, on the other, natural environments with varying levels of land use and perceptions of biodiversity and scenic beauty.

This study found that both meadow types are seen as very restorative places which provide many health benefits. Thus, extensively managed and abandoned meadows seem to have a potential for health. European mountain BRs typically include cultivated and natural landscapes, including extensively managed and unmanaged meadows. If future studies can provide empirical evidence of health benefits for both mountain meadow types, then such benefits can be used for health-related offers for tourists (Eder et al. 2015). In addition, their potential health effects should be considered in protected area management (e. g. in BRs), in political decision making, and in the design of agroenvironmental, public health and nature conservation policies and measures.

To our knowledge, this is the first study systematically to investigate perceived health effects of mountain meadows with different levels of naturalness. Additional studies comparing meadows with other alpine land-use types such as forests and pastures are necessary to gain a deeper understanding of the health effects of alpine landscapes. Additional studies may also assess physical health parameters such as cortisol levels (Lee et al. 2009), heart rate (Frohmann et al. 2010) or brain activity (Johansson et al. 2014).

\section{Acknowledgements}

This project was financed by the Earth-SystemScience-Progamme of the Austrian Academy of Sciences. We thank Martin Ebenberger, Andreas Bohner, Johannes Karrer, Ronnie Walcher, David Brandl, Leopold Sachslehner, Kerstin Michel, Georg Wanek, and all study participants for their assistance in the project.

\section{References}

Arnberger, A. \& R. Eder 2011. Exploring the heterogeneity of rural landscape preferences: an imagebased latent class approach. Landscape Research 36: 19-40.

Barton, J. \& J. Pretty 2010. What is the best dose of nature and green exercise for improving mental health? A multi-study analysis. Environmental Science \& Technology 44(10): 3947-3955.

Baur, B., H. Baur, C. Roesti \& D. Roesti 2006. Die Heuschrecken der Schweiz. Haupt, Bern.

Berto, R. 2005. Exposure to restorative environments helps restore attentional capacity. Journal of Environmental Psychology 25: 249-259.

Boschi, C. \& B. Baur 2008. Past pasture management affects the land snail diversity in nutrient-poor calcareous grasslands. Basic and Applied Ecology 9: 752761.

Bürgi, M., A. Straub, U. Gimmi \& D. Salzmann 2010. The recent landscape history of Limpach Valley, Switzerland: considering three empirical hypotheses on driving forces of landscape change. Landscape Ecology 25: 287-297.

Carrus, G., R. Lafortezza, G. Colangelo, I. Dentamaro, M. Scopelliti \& G. Sanesi 2013. Relations between naturalness and perceived restorativeness of different urban green spaces. Psyecology 4: 227-244.

Carrus, G., M. Scopelliti, R. Lafortezza, G. Colangelo, F. Ferrini, F. Salbitano, M. Agrimi, L. Portoghesi, P. Semenzato \& G. Sanesi 2015. Go greener, feel better? The positive effects of biodiversity on the well-being of individuals visiting urban and peri-urban green areas. Landscape and Urban Planning 134: 221-228. 
Chang, K.G., W.C. Sullivan, Y.-H. Lin, W. Su \& C.Y. Chang 2016. The effect of biodiversity on green spaces users' wellbeing - An empirical investigation using physiological evidence. Sustainability 8: 1049.

Dallimer, M., K.N. Irvine, A.M.J. Skinner, Z.G. Davies, J.R. Rouquette, L.L. Maltby, P.H. Warren, P.R. Armsworth \& K.J. Gaston 2012. Biodiversity and the feel-good factor: understanding associations between self-reported human well-being and species richness. BioScience 62: 47-55.

Eder, R., B. Allex \& A. Arnberger 2016. Einfluss von städtischen Erholungsgebieten auf Wohlbefinden, Konzentrationsfähigkeit und Stressempfinden von Jugendlichen. Umweltpsychologie 39(2): 15-35. In German]

Eder, R., A. Arnberger \& G. Köck 2015. Biosphere reserve landscapes as resources for human health and well-being. In Giorgi, A., A. Borsdorf, G. Köck \& T. Scheurer (eds.), Alpine Resources: Use, valorisation and management from local to macro-regional scale: 116-118. Milan.

Frohmann, E., V. Grote, A. Avian \& M. Moser 2010. Psychologische Effekte atmosphärischer Qualitäten der Landschaft. Schweizerische Zeitschrift für das Forstwesen 161(3): 97-103. [In German]

Fuller, R.A., K.N. Irvine, P. Devine-Wright, P.H Warren \& K.J. Gaston 2007. Psychological benefits of greenspace increase with biodiversity. Biology Letters 3: 390-394.

Han, K.T. 2010. An exploration of relationships among the responses to natural scenes: scenic beauty, preference, and restoration. Environment and Behavior 42(2): 243-270.

Hansmann, R., S.-M. Hug \& K. Seeland 2007. Restoration and stress relief through physical activities in forests and parks. Urban Forestry \& Urban Greening 6: 213-225.

Hartig, T. \& H. Staats 2006. The need for psychological restoration as a determinant of environmental preferences. Journal of Environmental Psychology 26: 215-226.

Hartig, T., K. Korpela, G.W. Evans \& T. Gärling 1997. A measure of restorative quality in environments. Scandinavian Housing \& Planning Research 14: 175-194.

Hartig, T., G.W. Evans, L.D. Jamner, D.S. Davis \& T. Gärling 2003. Tracking restoration in natural and urban field settings. Journal of Environmental Psychology 23(2): 109-123.

Hernández, B. \& M.C. Hidalgo 2005. Effect of urban vegetation on psychological restorativeness. Psychological Reports 96: 1025-1028.

Hersperger, A.M. \& M. Bürgi 2010. How do policies shape landscapes? Landscape change and its political driving forces in the Limmat Valley, Switzerland 1930-2000. Landscape Research 35: 259-279.

Herzog, T.R., C.P. Maguire \& M.B. Nebel 2003. Assessing the restorative components of environments. Journal of Environmental Psychology 23: 159-170.
Imes, C.C. \& L.E. Burke 2014. The obesity epidemic: The United States as a cautionary tale for the rest of the world. Current Epidemiology Reports 1(2): 82-88.

Johansson, M., M. Gyllin, J. Witzell \& M. Küller 2014. Does biological quality matter? Direct and reflected appraisal of biodiversity in temperate decidious broad-leaf forest. Urban Forestry \& Urban Greening 13: 28-37.

Kaplan, R. \& S. Kaplan 1989. The experience of nature. A psychological perspective. New York.

Keniger, L.E., K.J. Gaston, K.N. Irvine \& R.A. Fuller 2013. What are the benefits of interacting with nature? International Journal of Environmental Research and Public Health 10: 913-935.

Lee, J., B.-J. Park, Y. Tsunetsugu, T. Kagawa \& Y. Miyazaki 2009. Restorative effects of viewing real forest landscapes, based on a comparison with urban landscapes. Scandinavian Journal of Forest Research 24(3): 227-234.

Lovell, R., B.W. Wheeler, S.L. Higgins, K.N. Irvine \& M.H. Depledge 2014. A systematic review of the health and well-being benefits of biodiverse environments. Journal of Toxicology and Environmental Health, Part B: Critical Reviews 17(1): 1-20.

Marselle, M.R., K.N. Irvine, A. Lorenzo-Arribas \& S.L. Warber 2015. Moving beyond green: exploring the relationship of environment type and indicators of perceived environmental quality on emotional well-being following group walks. International Journal of Environmental Research and Public Health 12: 106-130.

Martens, D., H. Gutscher \& N. Bauer 2011. Walking in ,wild“ and „tended" urban forests: the impact on psychological well-being. Journal of Environmental Psychology 31: 36-44.

Millennium Ecosystem Assessment MA 2003. Ecosystems and Human Well-Being: A Framework for Assessment. Washington, DC.

Ranta, E. \& K. Vepsäläinen 1981. Why are there so many species? Spatio-temporal heterogeneity and northern bumblebee communities. Oikos 36(1): 28-34.

Rasch, D., M. Friese, W.J. Hofmann \& E. Naumann 2010. Quantitative Methoden, Band 2 (3. Auflage). Heidelberg.

Rom, F., A. Arnberger \& R.C. Burns 2013. Exploring differences in mountain landscape preferences and perceptions between Austrian and United States protected area visitors. eco.mont - Journal on Protected Mountain Areas Research and Management 5(2): 35-46.

Tasser, E. \& U. Tappeiner 2002. Impact of land use changes on mountain vegetation. Applied Vegetation Science 5: 173-184.

Tocco, C., M. Negro, A. Rolando \& C. Palestrini 2103. Does natural reforestation represent a potential threat to dung beetle diversity in the Alps? Journal of Insect Conservation 17: 207-217.

Tyrväinen, L., A. Ojala, K. Korpela, T. Lanki, Y. Tsunetsugu \& T. Kagawa 2014. The influence of urban green environments on stress relief measures: A 
field experiment. Journal of Environmental Psychology 38: $1-9$.

Ulrich, R.S. 1984. View through a window may influence recovery from surgery. Science 224 (4647): $420-421$

Ulrich, R.S., R.F. Simons, B.D. Losito, E. Fiorito, M.A. Miles \& M. Zelson 1991. Stress recovery during exposure to natural and urban environments. Journal of Environmental Psychology 1: 201-230.

UMG s.a. Wiesen im Biosphärenpark Großes Walsertal. Biosphärenpark Management der Regio Großes Walsertal: Dornbirn. [In German]

Van den Berg, A.E., S.L. Koole \& N.Y. van der Wulp 2003. Environmental preference and restoration: (How) are they related? Journal of Environmental Psychology 23: 135-146.

Van den Berg, A.E., J. Maas, R.A. Verheij \& P.P. Groenewegen 2010. Green space as a buffer between stressful life events and health. Social Science \& Medicine 70: 1203-1210.

Velarde, M.D., G. Fry \& M. Tveit 2007. Health effects of viewing landscapes - landscape types in environmental psychology. Urban Forestry \& Urban Greening 6: 199-212.

Walcher, R., J. Karrer, L. Sachslehner, A. Bohner, B. Pachinger, D. Brandl, J.G. Zaller, A. Arnberger \& T. Frank 2017. Diversity of bumblebees, heteropteran bugs and grasshoppers maintained by both: abandonment and extensive management of mountain meadows in three regions across the Austrian and Swiss Alps. Landscape Ecology 32: 1937-1951.

Wöran, B. \& A. Arnberger 2012. Exploring relationships between recreation specialization, restorative environments and mountain hikers' flow experience. Leisure Sciences 34(2): 95-114.

\section{Authors}

Arne Arnberger- corresponding author ${ }^{1}$

is an Associate Professor in protected area and recreation planning at at the University of Natural Resources and Life Sciences (BOKU). His research focuses on ecotourism, outdoor recreation, visitor monitoring, the relationships between landscape and human health, and landscape aesthetics.

\section{Renate Eder}

studied landscape planning and is a senior scientist at the BOKU. Her research focuses on outdoor recreation, landscape aesthetics, the relationships between landscape and human health, and environmental education.

\footnotetext{
Brigitte Allex

studied landscape planning and is a senior scientist at the BOKU. Her research focuses on outdoor rec-
}

reation, climate change impacts on vulnerable groups, and the relationships between landscape and human health.

\section{Hans-Peter Hutter ${ }^{2}$}

studied medicine and ecology in Vienna. He specializes in environmental health and preventive medicine, and works as a public health officer for the City of Vienna. Since 2015, he has been the deputy head of the Department of Environmental Health, Medical University Vienna.

\section{Peter Wallner ${ }^{2}$}

studied medicine in Vienna and has been working in the field of environmental health since 1989. His research focuses, inter alia, on public health, landscape and human health, indoor air pollution and human biomonitoring.

\section{Nicole Baver ${ }^{3}$}

is an environmental psychologist working at WSL. Her research focuses on attitudes towards landscape development (e.g. wilderness and re-wilding) and on the effects of different natural environments on psychological wellbeing and health.

\section{Johann G. Zaller ${ }^{4}$}

is an Associate Professor in ecology. His research focuses on the effects of human activities on animalplant interactions, biodiversity and associated ecosystem services, as well as on non-target effects of pesticides.

\section{Thomas Frank ${ }^{4}$}

is Full Professor and head of the Institute of Zoology at the BOKU. His research focuses on agroecology, biodiversity, plant-herbivore-predator interactions, biological pest control and pollination.

${ }^{1}$ Institute of Landscape Development, Recreation and Conservation Planning, Department of Spatial, Landscape and Infrastructural Sciences (BOKU), University of Natural Resources and Life Sciences Vienna, Austria.

${ }^{2}$ Department of Environmental Health, Center for Public Health, Medical University Vienna, Austria.

${ }^{3}$ Swiss Federal Institute for Forest, Snow and Landscape Research WSL, Economics and Social Sciences, Social Sciences in Landscape Research, Birmensdorf, Switzerland.

${ }^{4}$ Institute of Zoology, University of Natural Resources and Life Sciences Vienna, Austria. 